Research Article

\title{
Experimental Study on Pore Characteristics and Fractal Dimension Calculation of Pore Structure of Aerated Concrete Block
}

\author{
Jun Fu $1 D$ and Yue Yu $\mathbb{D}$ \\ School of Civil Engineering and Architecture, Zhejiang Sci-Tech University, Hangzhou 310018, China \\ Correspondence should be addressed to Jun Fu; fujun@zstu.edu.cn
}

Received 27 May 2019; Accepted 24 July 2019; Published 8 August 2019

Academic Editor: Claudio Mazzotti

Copyright ( 2019 Jun Fu and Yue Yu. This is an open access article distributed under the Creative Commons Attribution License, which permits unrestricted use, distribution, and reproduction in any medium, provided the original work is properly cited.

\begin{abstract}
It is important to control and predict the macroscopic properties through pore structure parameters of cement-based materials. Microscopic pore structure of concrete has many characteristics, such as sizes and disordered distribution. It is necessary to use fractal theory to describe the pore structure of concrete. In order to establish the relationship between the pore structure characteristics of aerated concrete and porosity, shape factor, pore superficial area, average pore diameter, and average diameter, the fractal dimension of the pore structure was used to evaluate the pore structure characteristics of aerated concrete. The X-ray computed tomography (CT) images of the aerated concrete block pore structure were obtained by using the XTH320 series X-ray three-dimensional microscope. The pore characteristics of aerated concrete block were studied according to Image-Pro Plus (IPP). Based on the research of the fractal dimension measurement methods, the proposed MATLAB program automatically determined the fractal dimension of the aerated concrete block pore structure images. The research results indicated that the small pores $(20 \mu \mathrm{m} \sim 60 \mu \mathrm{m})$ of aerated concrete block account for a large percentage compared with the large pores $(60 \mu \mathrm{m} \sim 400 \mu \mathrm{m}$ or more) from pore diameter distribution and the pore structure of aerated concrete block has obvious fractal features and the fractal dimension of aerated concrete block pore structure images were calculated to be in the range of 1.775-1.805. The pore fractal dimension has a strong correlation with the pore fractal characteristics of aerated concrete blocks. The fractal dimension of the pore structure linearly increases with porosity, shape factor, and pore surface area. The fractal dimension of the pore structure decreases with the average pore size and average diameter. Thus, the fractal dimension of the pore structure that is calculated by the MATLAB program based on fractal theory can be assumed as the integrative evaluation index for evaluating the pore structure characteristic of aerated concrete block.
\end{abstract}

\section{Introduction}

With the continuous promotion of energy conservation and emission reduction policies, the aerated concrete blocks are widely used in building engineering, due to their low density, thermal insulation property, sound insulation property, antiseismic property, and easy processing. It is recognized that these macroscopic properties of aerated concrete blocks depend on its pore structure [1-3]. Aerated concrete is a kind of cement-based materials. The internal pore structure of aerated concrete blocks is complex in shape, large in number, and complex in pore connectivity. Furthermore, the pores and microcracks in the cement concretes could cause the deterioration of the structures. Hence, the valid method is required to characterize the complexity and irregularity of the pore structure of the aerated concrete blocks effectively. In recent years, the good methods were found to improve the performance of cement concretes. Many researchers devote a great deal of energy to this research and achieved some good research results. One of the important methods is that the addition of siliceous fly ashes in cement concretes can change the microscopic pore structure and macroscopic properties $[4,5]$. In order to study the pore structure of aerated concrete block, fractal theory was introduced into the study. Many studies [6-11] have shown that the pore structure of concrete has obvious fractal 
feature. Analysis of the microscopic pore structure is of great significance for the study of its macroscopic properties [12] and the establishment of the concrete structure $3 \mathrm{D}$ numerical model [13].

Currently, the pore structure parameters are difficult to be characterized quantitatively with common methods in the reason of the complexity and irregularity of the pore structure. The studies [14-17] have indicated that the pore structure images were processed by Image-Pro Plus (IPP) and it could obtain pore structure parameters easily compared with mercury intrusion porosimetry (MIP). The parameters of aerated concrete pore structures mainly include porosity, shape factor, pore surface area, average pore size, and average diameter. Many researches indicated that porosity and pore surface area are important to the compressive strength of concrete, and average pore size and average diameter are the factors of the pore diameter distribution. The shape factor of pore structure has an effect on the establishment of internal pore channels in concrete. Thus, it is necessary to study the pore structure parameters in order to adjust macroscopic properties of aerated concrete.

With the further development of pore structure research, more and more theories and methods are introduced into the pore structure of porous materials research. In the 1960s, the French mathematician Mandelbrot [18] proposed a fractal method for solving the problem of the length of the British coastline and provided an effective means for studying the relationships between the microstructure and macroscopic properties of porous materials. Numerous studies $[8,19]$ have shown that the internal pore structure of concrete has strong fractal characteristics. Hammad and Issa [20] and Guo et al. [21] studied the cracks on the fracture surface of concrete and found that the cracks showed significant fractal characteristics. The larger the fractal dimension, the greater the fracture toughness of the fracture surface. The two unique features of fractal object images are self-similarity and scale invariance $[22,23]$. One of the most important features is self-similarity, which means that each piece of the fractal objects is geometrically similar to the whole. The calculation of fractal dimension is one of the main factors affecting the practical application of the fractal theory. Various types of fractal dimension calculation methods have been proposed, such as carpet covering method [24], box-counting dimension method [25], differential box-counting dimension method [26], Hausdorff dimension method [27], capacity dimension method, Brownian motion dimension method [28], and spectral number method. The fractal dimensions of pore surface, pore volume, and pore axis are calculated by these methods. Among these fractal dimension calculation methods, the box dimension method is the most common method on the analysis of the fractal dimension of concrete. In the specific application process, it is necessary to analyze the physical quantity of the research object. The calculated fractal dimension has practical significance and research value. Peng et al. [29-31] studied the calculation methods of fractal dimension of two-dimensional and three-dimensional digital images and the calculation of rock pore fractal dimension. Yang and Shao [32] realized the fractal dimension calculation of two-dimensional digital images through the MATLAB program. Jin et al. [33] obtained the relationships between the pore surface fractal dimension and the pore characteristic parameters of cement mortar based on the MIP method and fractal model. The pore structure parameters of concrete represent the complexity of pore structure.

The pore structure of aerated concrete block will not be damaged and be preserved completely by X-ray computed tomography (CT). The aerated concrete block CT slice images contain lots of pore structure information compared with the data measured based on the MIP method. Thus, MATLAB is used to process aerated concrete block pore structure slice images in this study. The Fraclab program was introduced to calculate the fractal dimension of pore structure images. The program-calculated value is compared to the theoretical value by the fractal dimension of the fractal images. The relationships between the fractal dimension of the pore structure and the pore characteristic parameters are studied based on the program calculation in this study, which is used to establish the relationships between the pore characteristic parameters and the macroscopic properties of the aerated concrete blocks.

\section{Experimental}

2.1. Materials. The aerated concrete blocks were provided by Zhejiang Hangshi Building Materials Company. Table 1 shows the performance parameters of the aerated concrete block.

The aerated concrete block specimens were cut into $50 \mathrm{~mm} \times 50 \mathrm{~mm} \times 50 \mathrm{~mm}$ cubes by using a cutting machine for X-ray computed tomography (CT), without any obvious saw marks on the specimen surface. In the cutting process, the stability of the cutting saw blade should be controlled to ensure the flatness of the cutting plane and avoid the damage of the pore structure.

2.2. CT Images of the Specimen. The CT images of the aerated concrete block specimen were tested using a XTH320 series X-ray three-dimensional microscope in the computed tomography laboratory of Zhejiang University. Figure 1 shows the XTH320 series X-ray three-dimensional microscope and the specimen pore structure slice image. Table 2 shows the performance parameters of the equipment. The slice distance of aerated concrete block is $0.04 \mathrm{~mm}$ in the study.

The test steps are as follows: (1) the specimen is placed on the sample holder of the XTH320 series X-ray three-dimensional microscope; (2) the test instrument supplies voltage and turns on X-ray; (3) the test software is started, the basic information of the specimen is inputted, and the specimen is rotated 360 degrees; (4) the test software calculates the digital matrix of images; (5) CT grayscale images of the specimen are outputted. Finally, 1205 aerated concrete block CT images were obtained. The article analyzes the pore characteristic parameters according to Image-Pro Plus (IPP) and the relationships of the pore fractal dimension and the pore structure characteristics based on the CT images of aerated concrete block specimen. 
TABLE 1: Aerated concrete block-related performance parameters.

\begin{tabular}{lcccc}
\hline Materials & $\begin{array}{c}\text { Volume dry density } \\
\left(\mathrm{kg} \cdot \mathrm{m}^{-3}\right)\end{array}$ & $\begin{array}{c}\text { Average compressive } \\
\text { strength }(\mathrm{MPa})\end{array}$ & $\begin{array}{c}\text { Postfreezing strength } \\
(\mathrm{MPa})\end{array}$ & $\begin{array}{c}\text { Thermal conductivity } \\
(\mathrm{W}) \cdot(\mathrm{m} \cdot \mathrm{K})^{-1}\end{array}$ \\
\hline Aerated concrete block & 619 & 5.2 & 3.4 & 0.153 \\
\hline
\end{tabular}

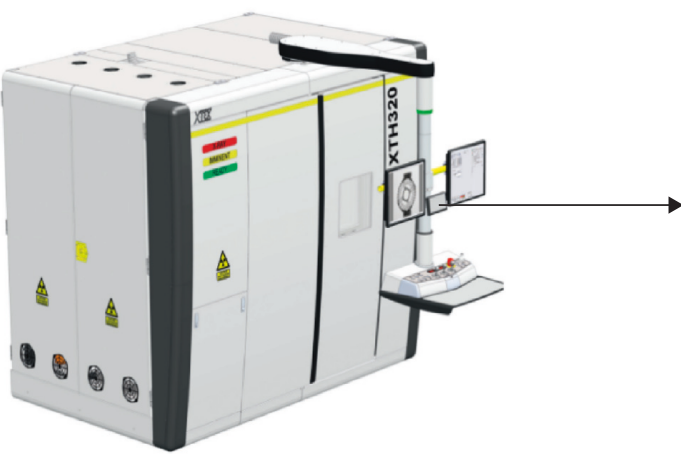

(a)

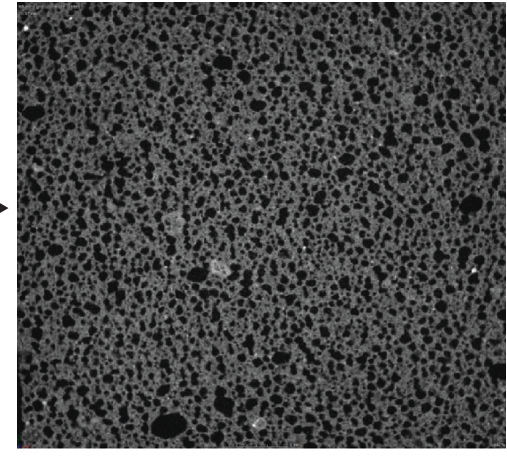

(b)

FIgURE 1: (a) XTH320 series X-ray three-dimensional microscope. (b) Test specimen pore structure slice image.

TABLE 2: XTH320 series X-ray three-dimensional microscope equipment performance parameters.

\begin{tabular}{lcccccc}
\hline $\begin{array}{l}\text { Device } \\
\text { parameters }\end{array}$ & $\begin{array}{c}\text { Highest voltage } \\
(\mathrm{kV})\end{array}$ & $\begin{array}{c}\text { Maximum current } \\
(\mu \mathrm{A})\end{array}$ & $\begin{array}{c}\text { Maximum power } \\
(\mathrm{W})\end{array}$ & $\begin{array}{c}\text { Filter }(\mathrm{Cu}) \\
(\mathrm{mm})\end{array}$ & $\begin{array}{c}\text { Resolution } \\
(\mu \mathrm{m})\end{array}$ & $\begin{array}{c}\text { Sample penetration } \\
(\mathrm{cm})\end{array}$ \\
\hline Parameter size & 320 & 1000 & 320 & $1 \sim 4$ & $5 \sim 50$ & $12 \sim 15$ \\
\hline 3. Methods & & & & & \\
$\ln [N(r)]=a+b \ln (r)$.
\end{tabular}

3.1. Pore Structure Characteristics Analytical Method. It can be seen that the aerated concrete block pore shape is complex and the pore number is numerous from Figure 1(b). It is difficult to characterize the pore structure by conventional statistical methods. In order to solve this problem, IPP software was used to study CT images of aerated concrete block pore structures. It can obtain the following pore structure characteristic parameters: characterizing porosity, pore shape factor, pore surface area, and average diameter. The specific steps and methods of image processing are not specifically described here. You can refer to the relevant literatures [34-36] for further researching. Figure 2 shows the process of IPP image processing.

\subsection{Fractal Model Based on the Box Dimension Method.} The box-counting dimension method $[37,38]$ is one of the classic methods for calculating the fractal dimension of images. First, the image is binarized and the binarized image is placed on the flat. The square image with the side length $r$ is used to cover the entire image. In the case of constantly changing the square grid size $r$, the number $N(r)$ of square grids covering the image of interest corresponding to each size $r$ is counted. If the relationship between the mesh size $r$ and the number of boxes $N(r)$ meets the following formula:

$$
N(r)=c \cdot r-D,
$$

where $c$ is a constant and $D$ is the box count. In the case application process, a series of data corresponding to $[r, N(r)]$ can be measured and calculated. The least squares method is used to fit the formula:
The box-counting dimension $D=b$ of the image can be obtained.

3.2.1. Fractal Dimension Calculation Based on MATLAB. The fractal dimension of the aerated concrete block pore structure images were calculated using the MATLAB program based on the box dimension method. The original image needs to be preprocessed by MATLAB in order to improve the image quality. The preprocessed image is converted into a binarized digital matrix. We can use the transformed binary image digital matrix when the researched portion of interest in the binarized image is white. If the imaged researched portion of the binarized image after image processing is black, we need the binarized digital matrix after the image is inverted. Figure 3 shows the results of the binarization processing of the Koch curve image by MATLAB.

The Fraclab program is called in the MATLAB command line, and the program automatically calculates the inverted binarized image. The maximum and minimum size of the box and the number of boxes can be automatically identified by the program. The box dimension is the program calculation fractal dimension value $D=1.2356$ of the Koch curve image.

3.2.2. Program Calculation Verification. Table 3 shows the comparisons of the results of the calculation. It can be seen from Table 3 that the calculated relative deviation for the fractal image is $3.05 \%$ at maximum and the minimum deviation is $0.49 \%$. The relative deviation of the program for the fractal 


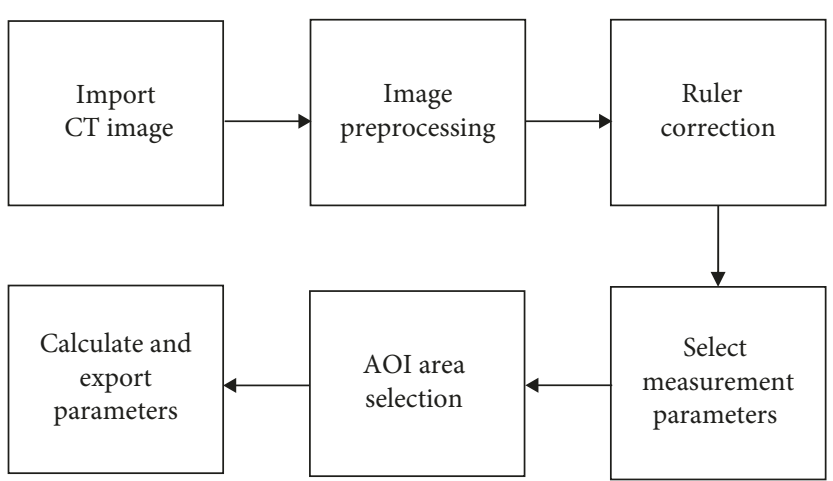

FIGURE 2: Image processing flow chart based on IPP.
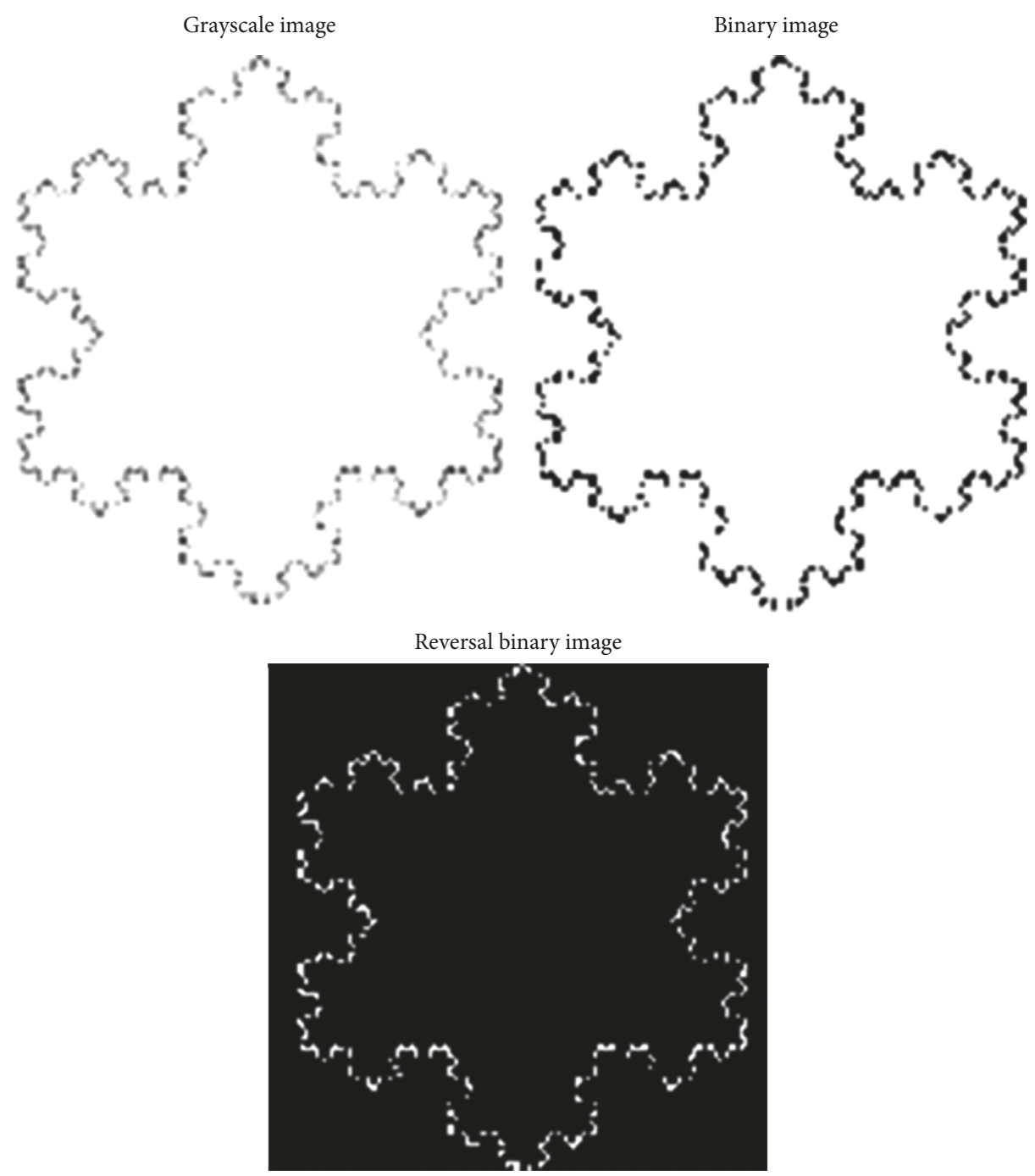

FIgURE 3: Koch curve image binarization preprocessing.

dimension of the Sherpinski triangle and the Sherpinsky square is $1.22 \%$ and $0.998 \%$. The relative deviation of the fractal dimension calculated for the Koch curve is $2.01 \%$. The cause of the deviation may be that the detailed image of the corner of the Koch curve is not clear enough. The numerical deviation of the image box calculated by MATLAB is less than $4 \%$. Thus, it can be used for the calculation and analysis of the actual image fractal dimension.

\section{Experimental Results and Discussion}

4.1. Pore Structure Characteristics. In order to study the pore structure characteristics of the aerated concrete block 
TABLE 3: Comparison of calculated value and theoretical value of the fractal image based on MATLAB.

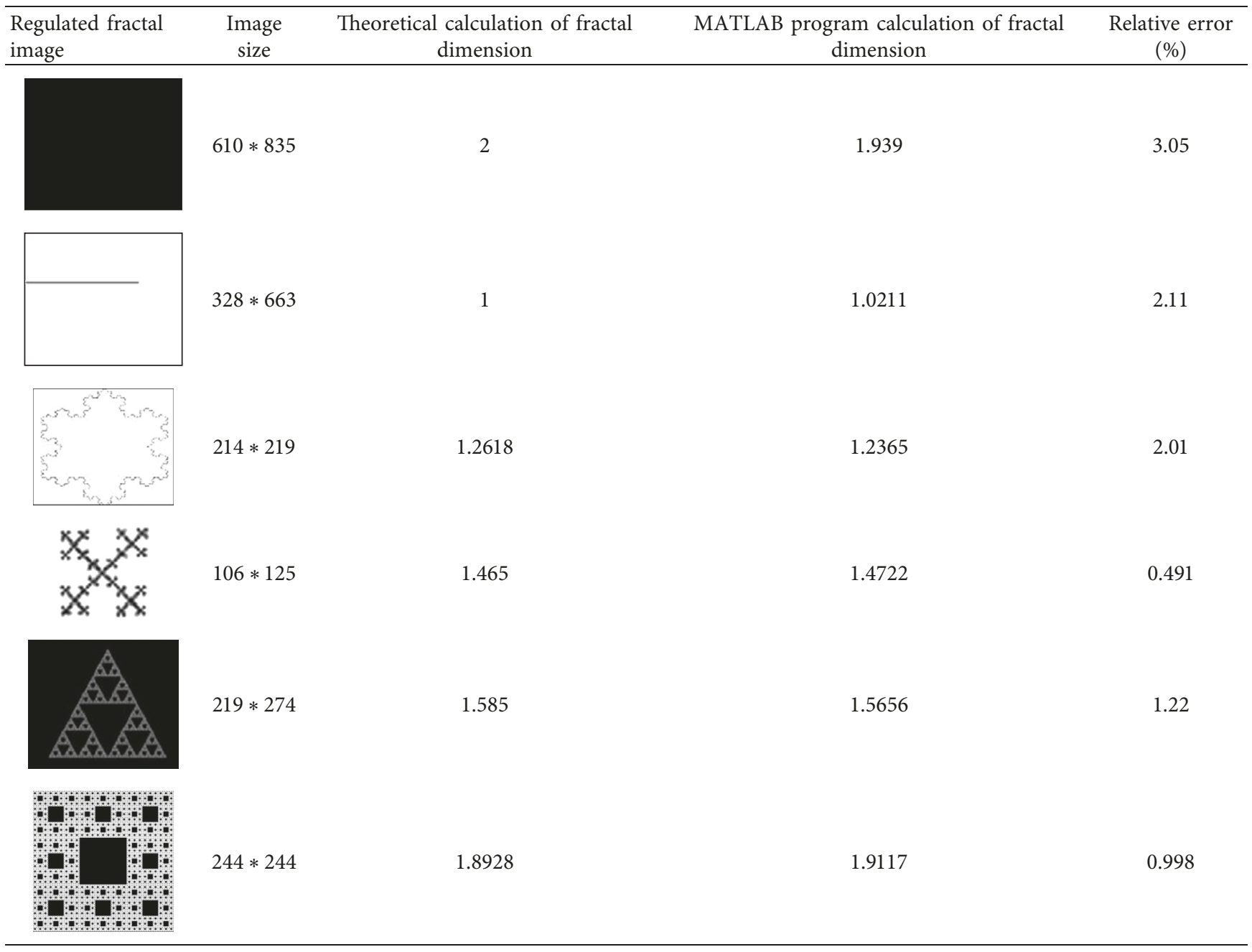

TABle 4: Pore structure parameters of the aerated concrete block (top).

\begin{tabular}{lccc}
\hline Specimen & Shape factor & Per area (obj./total) & Feret (mean) \\
\hline l\#top & 3.33 & 0.60 & 45.97 \\
2\#top & 2.71 & 0.61 & 39.74 \\
3\#top & 1.74 & 0.69 & 35.81 \\
4\#top & 1.89 & 0.63 & 137.65 \\
5\#top & 4.87 & 0.56 & 76.96 \\
Average & 2.91 & 0.62 & 67.23 \\
\hline
\end{tabular}

specimen completely, five pore structure slice images were taken from the upper, middle, and bottom parts of the specimen for analysis. The data of pore structure measurement parameters calculated based on IPP were statistically analyzed as follows. Tables 4-6, respectively, correspond to the pore structure characterization parameters of the upper, middle, and bottom parts of the aerated concrete block specimen. Taking Table 4 as an example, it can be seen that the pore shape factor of the aerated concrete block is 2.91 and the Feret diameter is 67.23 . The total percentage of pore area is
TABLE 5: Pore structure parameters of the aerated concrete block (middle).

\begin{tabular}{lccc}
\hline Specimen & Shape factor & Per area (obj./total) & Feret (mean) \\
\hline 1\#middle & 4.95 & 0.57 & 75.69 \\
2\#middle & 3.23 & 0.64 & 55.99 \\
3\#middle & 3.35 & 0.64 & 65.37 \\
4\#middle & 3.47 & 0.64 & 67.48 \\
5\#middle & 1.93 & 0.70 & 39.15 \\
Average & 3.38 & 0.64 & 60.74 \\
\hline
\end{tabular}

TABLE 6: Pore structure parameters of the aerated concrete block (bottom).

\begin{tabular}{lccc}
\hline Specimen & Shape factor & Per area (obj./total) & Feret (mean) \\
\hline 1\#bottom & 2.01 & 0.70 & 43.41 \\
2\#bottom & 2.04 & 0.69 & 41.14 \\
3\#bottom & 4.51 & 0.64 & 93.53 \\
4\#bottom & 4.49 & 0.64 & 93.27 \\
5\#bottom & 2.53 & 0.68 & 55.91 \\
Average & 3.12 & 0.67 & 65.45 \\
\hline
\end{tabular}




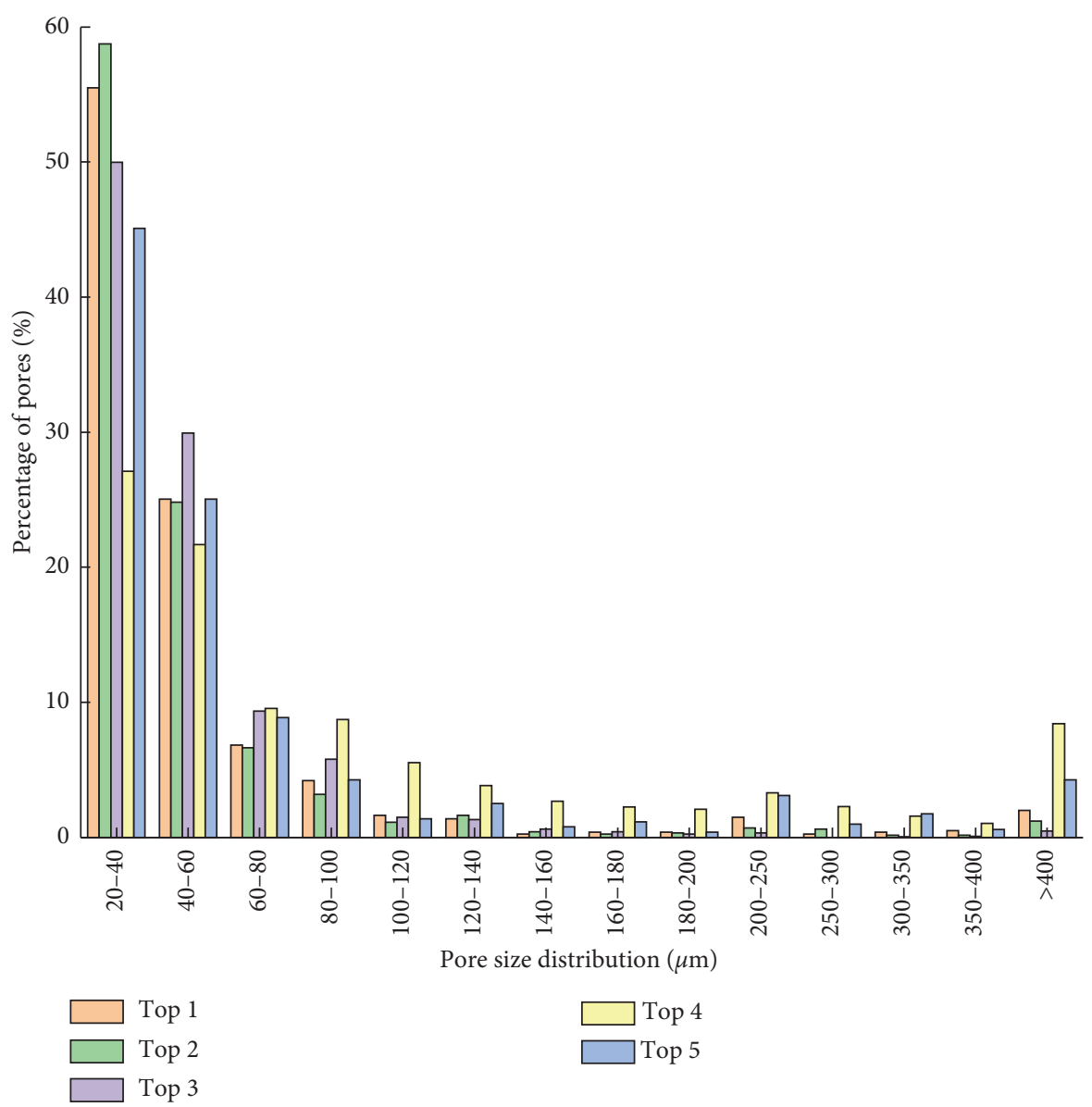

Figure 4: Pore size distribution of the aerated concrete block (top).

62\%. According to the stereological principle, $62 \%$ can be taken as the characterization porosity of the aerated concrete block. According to the statistics of the characteristic parameters of the pore structure in the upper, middle, and bottom parts of the aerated concrete block, the results show that the porosity of the aerated concrete block is $64.33 \%$ according to IPP. It can be seen that the irregular shape of the pore structure inside the aerated concrete block occupies a large percentage, which is mainly caused by the gas generation mode in the production process of the aerated concrete block. These parameters can provide reference indexes for pore structure control, raw material ratio, and block quality control of porous materials.

4.2. Pore Diameter Distribution. The pore diameter distribution can describe the size distribution form of the inner pore structure of the aerated concrete block. In the study, five pore structure slice images were taken from the upper, middle, and bottom parts of the specimen for analysis. The data of the pore diameter distribution were determined by 15 slices of the CT pore structure images. All pores structure slice images are from one scanning sample. The selection of the sample meets the research of the literature [34]. The average diameter distribution histogram is made to represent the pore diameter distribution diagram of the aerated concrete block based on fifteen pore structure slice images. Figures $4-6$ show the pore size distribution of the upper, middle, and bottom of the aerated concrete block and have similar trends. The pores $(20 \mu \mathrm{m} \sim 60 \mu \mathrm{m})$ are called macroscopic capillary pores. It can be seen from the pore size distribution diagram of the three parts that the small pores $(20 \mu \mathrm{m} \sim 60 \mu \mathrm{m})$ of the aerated concrete block account for a large percentage compared with the large pores $(60 \mu \mathrm{m} \sim 400 \mu \mathrm{m}$ or more). The macroscopic capillary pores are common in the interior of aerated concrete block.

4.3. Fractal Dimension of Pore Structure Images. The fractal dimension values of the 1205 pore structure images were calculated and counted by the MATLAB program. The fractal dimension of the aerated concrete block pore structure images is between 1.775 and 1.805, and the average fractal dimension is 1.789 .

Figure 7 shows that the fractal dimension of the pore structure images decrease with the depth of the slice. The fractal dimension of the initial pore structure image is larger than the following images. It is attributed to the irregular cutting surface owing to the cemented carbide saw. The fractal dimension of the pore structure slice images are distributed in two strip-shaped areas. It is necessary to find and study the relationships between the pore structure 

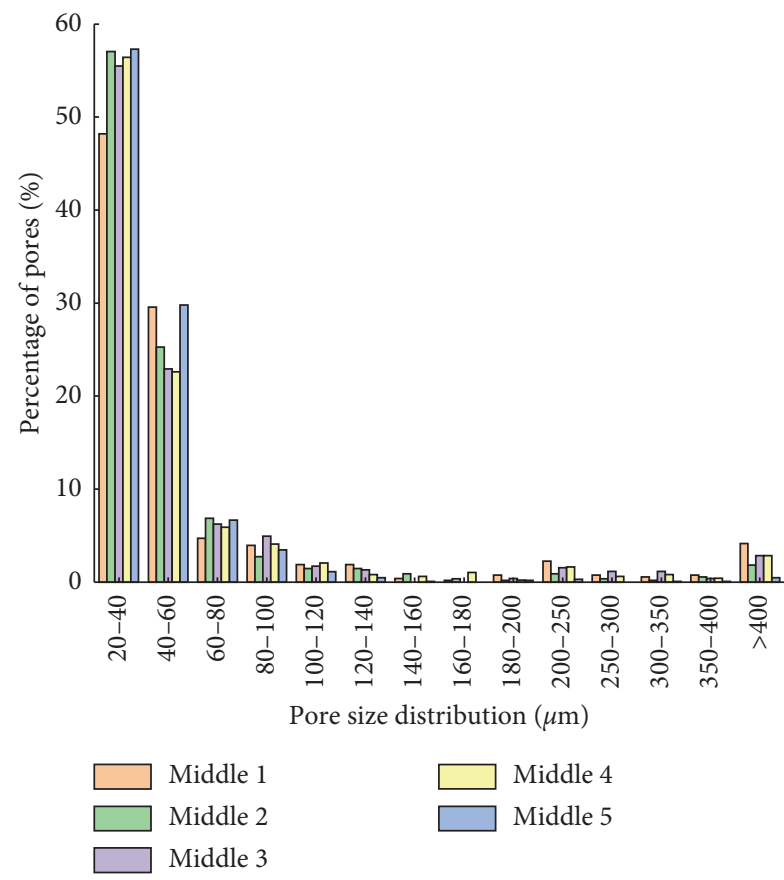

Figure 5: Pore size distribution of the aerated concrete block (middle).

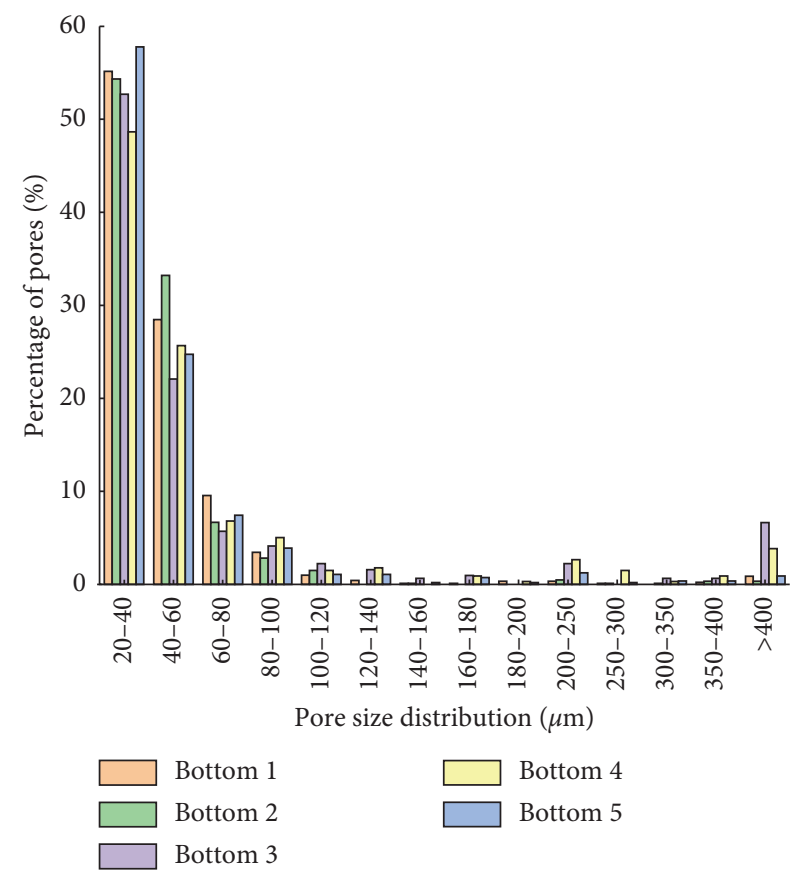

Figure 6: Pore size distribution of the aerated concrete block (bottom).

parameters and pore fractal dimension. We expect to use the pore fractal dimension to evaluate the complexity and irregularity of the pore structure of the aerated concrete blocks effectively.

A total of 25 CT images (one for every 50 sheets) were selected to process, and the corresponding pore structure parameters were obtained. The fractal dimension of the pore structure images that was calculated by the

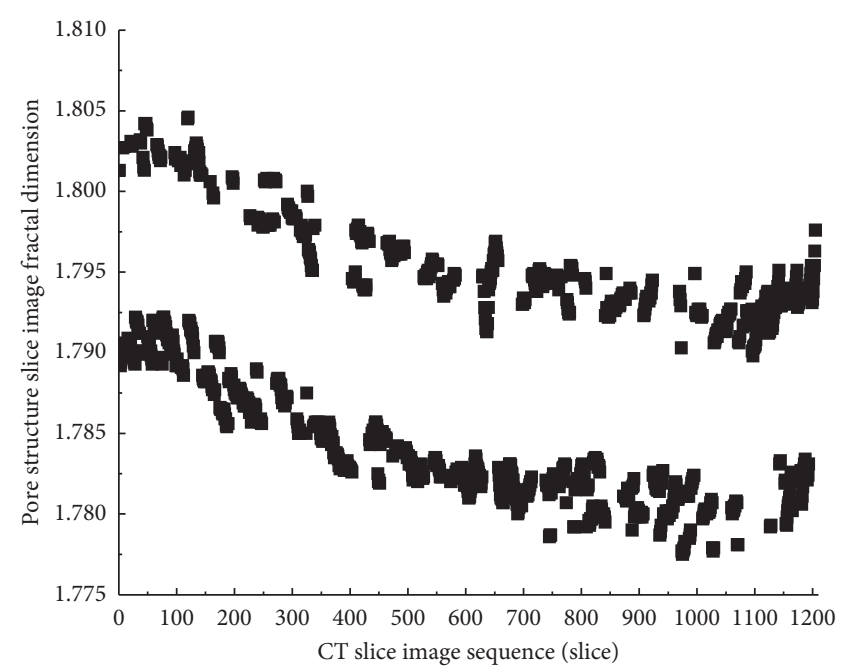

Figure 7: Statistical analysis of fractal dimension of the CT slice image of the aerated concrete block sample.

MATLAB program and the pore structure characteristic parameters that were calculated by IPP are shown in Table 7. The relationships between the fractal dimension and the characteristic parameters are shown in Figures 8-12.

4.3.1. Relationship between Pore Fractal Dimension and Porosity. The porosity of aerated concrete block is one of the fatal macroscopic performance indexes. The macroscopic performance of the aerated concrete block depends on porosity, such as penetrating quality, thermal insulation property, and sound insulation property. Therefore, studying the porosity of aerated concrete blocks is conductive to the further development of its macroscopic performance research. Figure 8 shows that the pore fractal dimension linearly increases with the porosity. As can be seen from Figure 8, a good correlation exits between porosity and pore fractal dimension and the regression coefficient $R^{2}$ of 0.8359 indicates that the correlation between the pore fractal dimension and the porosity is strong. The porosity increases with the fractal dimension of the pore structure. Fractal dimension represents the complexity of the pore structure images [33]. It indicates that the spatial occupancy of pore structure increases when the porosity increases. And lots of pore structures that overlap and cross lead to more complex pore structure shapes. The results are consistent with the views of Yu et al. [39] and Xie et al. [40]. It can be noted from our results that the calculated method of fractal dimension is useful. Results of previous works have shown that the porosity is the main factor affecting the permeability and thermal insulation properties of aerated concrete blocks. In order to meet the requirement of thermal insulation properties of aerated concrete blocks, many companies research the new mix proportioning of aerated concrete blocks and it is kept secret from the outside world. The conventional porosity of aerated concrete blocks which many companies proposed is $65 \%$ $85 \%$. From the above analysis, the pore fractal dimension has a strong correlation 
TABLe 7: Fractal dimension value and pore structure parameters of aerated concrete block slice images.

\begin{tabular}{|c|c|c|c|c|c|c|}
\hline Slice image serial number & $\begin{array}{c}\text { Pore fractal } \\
\text { dimension }\end{array}$ & $\begin{array}{l}\text { Pore surface } \\
\text { area }\left(\mathrm{mm}^{2}\right)\end{array}$ & Average diameter $(\mathrm{mm})$ & Shape factor & Porosity (\%) & $\begin{array}{l}\text { Average pore } \\
\text { size }(\mathrm{mm})\end{array}$ \\
\hline TOP001 & 1.8013 & 576.43 & 0.0979 & 2.7408 & 72.00 & 0.0720 \\
\hline TOP051 & 1.7909 & 630.31 & 0.1190 & 2.2716 & 69.63 & 0.1039 \\
\hline TOP101 & 1.7896 & 387.72 & 0.1189 & 2.0649 & 66.32 & 0.1067 \\
\hline TOP151 & 1.7882 & 305.77 & 0.1315 & 2.0131 & 64.41 & 0.1307 \\
\hline TOP201 & 1.7875 & 325.77 & 0.1373 & 1.8923 & 62.63 & 0.1330 \\
\hline TOP251 & 1.7979 & 565.09 & 0.1075 & 2.6218 & 72.66 & 0.0860 \\
\hline TOP301 & 1.7983 & 591.38 & 0.1122 & 2.5251 & 71.41 & 0.0931 \\
\hline TOP351 & 1.7847 & 127.96 & 0.1687 & 1.7471 & 59.08 & 0.1813 \\
\hline TOP401 & 1.7828 & 115.99 & 0.1684 & 1.7288 & 58.21 & 0.1819 \\
\hline TOP451 & 1.7819 & 121.21 & 0.1746 & 1.6972 & 57.80 & 0.1897 \\
\hline TOP501 & 1.7836 & 101.35 & 0.1845 & 1.6799 & 57.39 & 0.2017 \\
\hline TOP551 & 1.7955 & 673.84 & 0.1369 & 2.2237 & 67.32 & 0.1306 \\
\hline TOP601 & 1.7819 & 96.80 & 0.1933 & 1.6892 & 56.65 & 0.2139 \\
\hline TOP651 & 1.7968 & 673.20 & 0.1398 & 2.1855 & 67.19 & 0.1330 \\
\hline TOP701 & 1.7933 & 689.55 & 0.1406 & 2.1390 & 66.25 & 0.1345 \\
\hline TOP751 & 1.7822 & 77.28 & 0.1958 & 1.6561 & 56.70 & 0.2159 \\
\hline TOP801 & 1.7830 & 81.46 & 0.2004 & 1.6857 & 56.97 & 0.2238 \\
\hline TOP851 & 1.7929 & 668.68 & 0.1417 & 2.2726 & 67.60 & 0.1373 \\
\hline TOP901 & 1.7798 & 154.53 & 0.1894 & 1.7849 & 58.44 & 0.2095 \\
\hline TOP951 & 1.7800 & 158.64 & 0.1926 & 1.7823 & 59.22 & 0.2156 \\
\hline TOP1001 & 1.7925 & 591.57 & 0.1229 & 2.6484 & 71.50 & 0.1078 \\
\hline TOP1051 & 1.7914 & 235.43 & 0.1769 & 1.9227 & 61.80 & 0.1912 \\
\hline TOP1101 & 1.7905 & 314.21 & 0.1643 & 2.0033 & 63.68 & 0.1744 \\
\hline TOP1151 & 1.7940 & 665.94 & 0.1561 & 2.2238 & 67.46 & 0.1561 \\
\hline TOP1201 & 1.7938 & 257.03 & 0.1834 & 2.1431 & 65.25 & 0.1995 \\
\hline
\end{tabular}

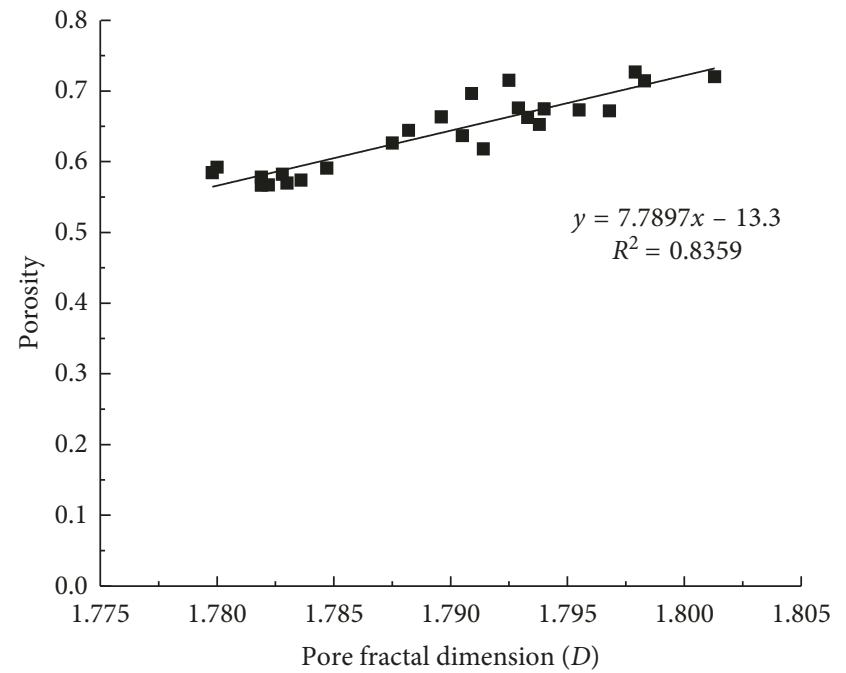

Figure 8: Relationship between pore fractal dimension and porosity.

with the porosity. Therefore, the porosity of the aerated concrete block can be indirectly evaluated by the fractal dimension of the pore structure images. The pore fractal dimension should be used to predict the permeability of the aerated concrete block effectively.

4.3.2. Relationship between Pore Fractal Dimension and Shape Factor. Shape factor is also one of the important parameters of pore structure characterization. It is an

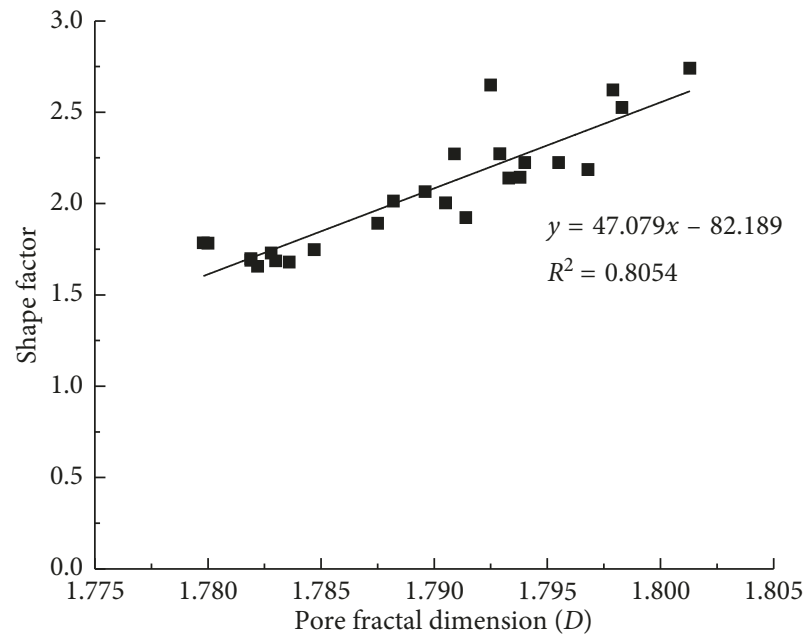

FIGURE 9: Relationship between pore fractal dimension and shape factor.

important indicator to characterize whether the shape of the pore structure is close to a circle. The pore structure shape plays an important role in the formation of internal pore channels of porous materials. It stipulates that the shape factor of the sphere is 1 and the larger the value corresponding to the shape factor, the higher the degree of deviation from the sphere. Figure 9 shows that the linear correlation coefficient $R^{2}$ between the fractal dimension and the shape factor reaches 0.8054 . As the pore structure fractal dimension increases, the shape factor of the pore structure also increases. It indicates that the shape of the pore structure 


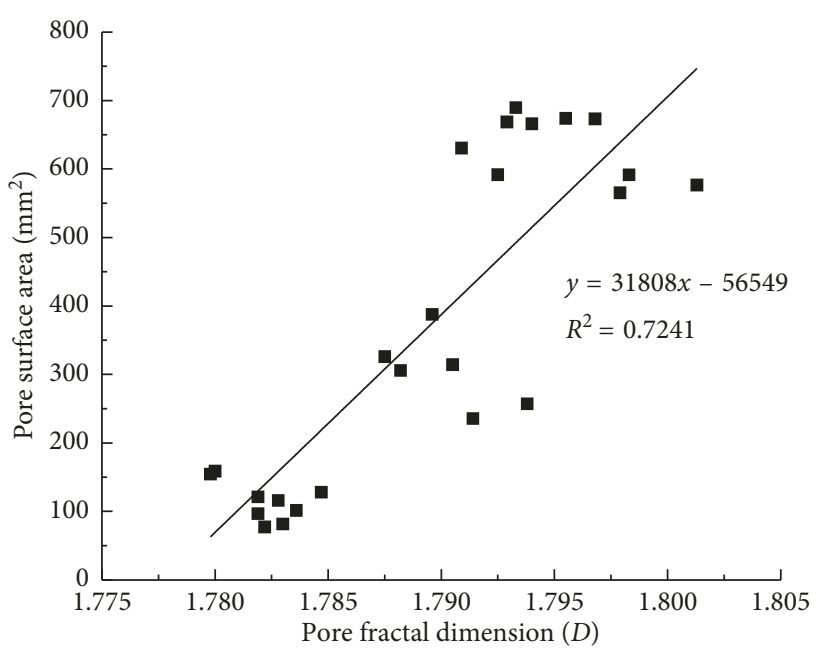

FIGURE 10: Relationship between pore fractal dimension and pore surface area.

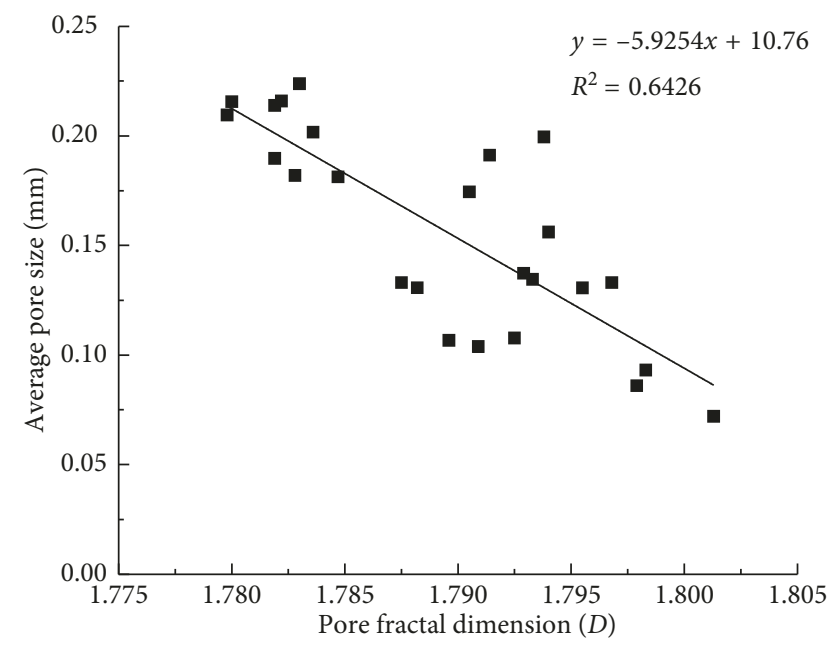

FIGURE 11: Relationship between pore fractal dimension and average pore size.

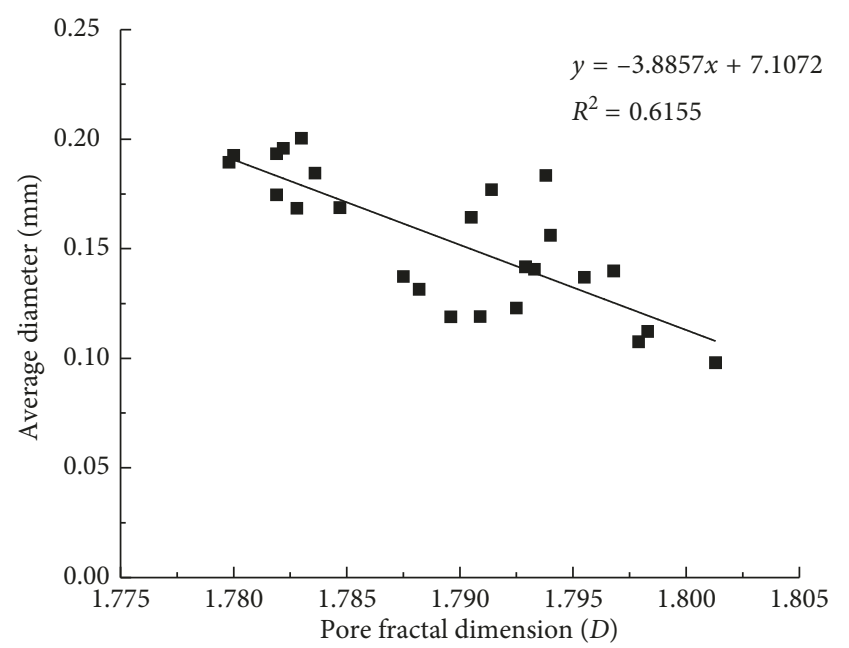

FIGURE 12: Relationship between pore fractal dimension and the average diameter. deviates more from the circular shape, which is similar to the relationship between the pore fractal dimension and the porosity given in Section 4.4.1. Results of previous works have shown that the shape factor has a decrease trend with density of concrete [41]. According to the principle, the larger the density, the more circle the pore structure of the aerated concrete block. Therefore, the pore fractal dimension can be used to characterize the degree of deviation of the pore structure from the circular shape. That is, the pore fractal dimension has a decrease trend with density of aerated concrete block. Thus, the pore fractal dimension can evaluate the density of the aerated concrete block. Finally, it can be used as a reference for the subsequent establishment of the cross-sectional shape of the threedimensional aerated concrete block pore channel and the establishment of the pore channel of the aerated concrete block.

4.3.3. Relationship between Pore Fractal Dimension and Pore Surface Area. Many researches indicated that the pore surface area is related to the degree of hydration of aerated concrete. As the pore surface area increases, the degree of hydration of aerated concrete also increases. The degree of hydration of aerated concrete is also related to the compressive strength of concrete. It shows that the strength of concrete increases rapidly in the early stage and slowly in the later stage. That is, the compressive strength linearly increases with the pore surface area. Figure 10 shows that the linear equation coefficient $R^{2}$ between the pore fractal dimension and the pore surface area reaches 0.7241 . It indicates that the pore fractal dimension has a good correlation with the pore surface area. In the case of the same porosity, the smaller the pore surface area, the smaller the number of pores with a small pore diameter and the lower the roughness of the pore surface. The roughness and pore size distribution of the pore surface can be evaluated by the pore fractal dimension. The compressive strength linearly increases with pore fractal dimension combined with above analysis. Finally, the compressive strength of aerated concrete block can be evaluated by pore fractal dimension.

4.3.4. Relationship between Pore Fractal Dimension and Average Pore Size and Average Diameter. The average pore size and average diameter are parameters that characterize the average size of the pore structure and are usually applied to the pore size distribution. There are many factors affecting the average pore diameter of the aerated concrete block, including raw material, technological parameters, and curing conditions. An interesting phenomenon from Table 7 can be found that the size of average pore diameters is discontinuous. The reason is that pore structure images contain the macroscopic pores and the macroscopic pores would appear and disappear continuously with the increase in the slice depth. So the relationship of the pore fractal dimension and average pore diameters should be established. Thus, the relationship research of pore structure parameters and pore fractal dimension is necessary. Figures 11 and 12 show that the linear equation correlation 
coefficient $R^{2}$ between the pore fractal dimension and the average pore size and the average diameter is 0.6426 and 0.6155 . The average pore size and average diameter show the same changing trend with an increase in the fractal dimension. In other words, average pore size and average diameter show an obvious decreasing trend with increasing fractal dimension. This finding is consistent with the results reported in the literature of Jin et al. [33]. It can be noted from our results that the calculated method of fractal dimension is useful. According to fractal theory, the larger the pore fractal dimension, the smaller the average size of the hole and the more complex the spatial distribution of pores in the aerated concrete block. It indicates that the amount of small holes is increasing. In the case of the same porosity of the aerated concrete block, the larger the average pore diameter and the average diameter, the smaller the amount of holes and the thicker the pore wall of the corresponding pore structure. The results show that the pore fractal dimension can describe the pore size distribution and it also paves the way for the subsequent study of the relationship between the fractal dimension and capillary water pressure.

\section{Conclusions}

This paper studied the pore structure parameters based on IPP and introduced the calculation method of fractal dimension according to MATLAB. The relationships between pore structure fractal dimension and pore structure parameters were researched. Based on the experimental results from this study, the following conclusions can be drawn:

(1) The small pores $(20 \mu \mathrm{m} \sim 60 \mu \mathrm{m})$ of aerated concrete block account for a large percentage compared with the large pores $(60 \mu \mathrm{m} \sim 400 \mu \mathrm{m}$ or more) from pore diameter distribution.

(2) The pore fractal dimension of aerated concrete block is between 1.775 and 1.805 .

(3) The pore fractal dimension of aerated concrete block has the strong correlation with porosity and pore shape factor.

(4) The pore fractal dimension of aerated concrete block is well correlated with the pore surface area. The size of pore fractal dimension can effectively characterize the roughness and pore size distribution of pore surface.

(5) The correlation between the pore fractal dimension of the aerated concrete block and the average pore diameter and average diameter is general. The pore fractal dimension can be used as an index to evaluate the average pore size and pore diameter distribution. When the pore fractal dimension is larger, the average pore size is smaller, and when the porosity is larger, the pore structure is degraded.

\section{Data Availability}

The data used to support the findings of this study are available from the corresponding author upon request.

\section{Conflicts of Interest}

The authors declare that they have no conflicts of interest.

\section{Acknowledgments}

This research was funded by the Zhejiang Basic Public Welfare Research Project (LGF8E080016) and China Association for Engineering Construction Standardization.

\section{References}

[1] Y. Song, C. A. Davy, D. Troadec, and X. Bourbon, "Pore network of cement hydrates in a high performance concrete by $3 \mathrm{D}$ FIB/SEM-implications for macroscopic fluid transport," Cement and Concrete Research, vol. 115, pp. 308-326, 2019.

[2] X. Wang, P. Sun, N. Han, and F. Xing, "Experimental study on mechanical properties and porosity of organic microcapsules based self-healing cementitious composite," Materials, vol. 10, no. 1, p. 20, 2017.

[3] F. Xu, G. Gu, W. Zhang, H. Wang, X. Huang, and J. Zhu, "Pore structure analysis and properties evaluations of fly ashbased geopolymer foams by chemical foaming method," Ceramics International, vol. 44, no. 16, pp. 19989-19997, 2018.

[4] G. L. Golewski and T. Sadowski, "Macroscopic evaluation of fracture processes in fly ash concrete," Solid State Phenomena, vol. 254, pp. 188-193, 2016.

[5] G. L. Golewski, "The influence of microcrack width on the mechanical parameters in concrete with the addition of fly ash: consideration of technological and ecological benefits," Construction and Building Materials, vol. 197, pp. 849-861, 2019.

[6] S. Cui, P. Liu, E. Cui, J. Su, and B. Huang, "Experimental study on mechanical property and pore structure of concrete for shoetree use in a hot-dry environment of high geothermal tunnels," Construction and Building Materials, vol. 173, pp. 124-135, 2018.

[7] V. N. Zarnaghi, A. Fouroghi-Asl, V. Nourani, and H. Ma, “On the pore structures of lightweight self-compacting concrete containing silica fume," Construction and Building Materials, vol. 193, pp. 557-564, 2018.

[8] Y. Chen and Y. F. Xu, "Compressive strength of fractaltextured foamed concrete," Fractals-Complex Geometry Patterns and Scaling in Nature and Society, vol. 27, no. 1, article 1940003, 2019.

[9] Y. Guo, J. Qian, and X. Wang, "Pore structure and influence of recycled aggregate concrete on drying shrinkage," Mathematical Problems in Engineering, vol. 2013, Article ID 912412, 7 pages, 2013.

[10] J. Konkol and G. Prokopski, "The use of fractal geometry for the assessment of the diversification of macro-pores in concrete," Image Analysis \& Stereology, vol. 30, no. 2, pp. 89-100, 2011.

[11] S.-B. Zhou, J.-L. Liang, W.-A. Xuan, and Y. Qiu, "The correlation between pore structure and macro durability performance of road concrete under loading and freeze-thaw and drying-wetting cycles," Advances in Materials Science and Engineering, vol. 2017, Article ID 5015169, 6 pages, 2017.

[12] S. Jin, J. Zhang, and S. Han, "Fractal analysis of relation between strength and pore structure of hardened mortar," Construction and Building Materials, vol. 135, pp. 1-7, 2017. 
[13] B. Mou, X. Li, Q. Y. Qiao, B. J. He, and M. L. Wu, "Seismic behaviour of the corner joints of a frame under biaxial cyclic loading," Engineering Structures, vol. 196, article 109316, 2019.

[14] X. He, J. Yin, J. Yang, Q. Liang, and S. Wu, "Effect of day-wet circulation on the mechanical properties and pore structure of autoclaved aerated concrete," Materiali in Tehnologije, vol. 53, no. 2, pp. 177-182, 2019.

[15] A. Nadeem, S. A. Memon, and T. Y. Lo, "Qualitative and quantitative analysis and identification of flaws in the microstructure of fly ash and metakaolin blended high performance concrete after exposure to elevated temperatures," Construction and Building Materials, vol. 38, pp. 731-741, 2013.

[16] A. Nadeem, S. A. Memon, and T. Y. Lo, "The performance of fly ash and metakaolin concrete at elevated temperatures," Construction and Building Materials, vol. 62, pp. 67-76, 2014.

[17] M. M. Vlahovic, M. M. Savic, S. P. Martinovic, T. D. Boljanac, and T. D. Volkov-Husovic, "Use of image analysis for durability testing of sulfur concrete and Portland cement concrete," Materials \& Design, vol. 34, pp. 346-354, 2012.

[18] A. Gabriele, D. R. Losa, R. Dejan, Z. Ivan, and B. Stefano, "From fractal geometry to fractal analysis," Applied Mathematics, vol. 7, no. 4, pp. 346-354, 2016.

[19] L. Zhao, W. Wang, Z. Li, and Y. F. Chen, "Microstructure and pore fractal dimensions of recycled thermal insulation concrete," Materials Testing, vol. 57, no. 4, pp. 349-359, 2015.

[20] A. M. Hammad and M. A. Issa, "Fractal dimension as a measure of roughness of concrete fracture trajectories," Advanced Cement Based Materials, vol. 1, no. 4, pp. 169-177, 1994.

[21] D. M. Guo, J. P. Zuo, H. Zhang, and H. Xu, "Mechanics of crack propagation in high performance concrete and its fractal dimensions based on ct observation," Journal of the Chinese Ceramic Society, vol. 37, pp. 1607-1612, 2009.

[22] I. V. Volvenko, "The multidimensional space of the integral characteristics of biocenotic assemblages: the self-similarity or scale invariance of its structure," Russian Journal of Marine Biology, vol. 38, no. 7, pp. 509-519, 2012.

[23] H. Wendt, G. Didier, S. Combrexelle, and P. Abry, "Multivariate hadamard self-similarity: testing fractal connectivity," Physica D-Nonlinear Phenomena, vol. 356, pp. 1-36, 2017.

[24] A. K. Sidhu and J. S. Sivia, "A novel design of wideband koch like sided sierpinski square carpet multifractal antenna," Applied Computational Electromagnetics Society Journal, vol. 33, pp. 873-879, 2018.

[25] W. Song, D. Wang, J. Yao et al., "Multiscale image-based fractal characteristic of shale pore structure with implication to accurate prediction of gas permeability," Fuel, vol. 241, pp. 522-532, 2019.

[26] S. Ebrahimi, M. B. Tavakolii, and F. Setoudeh, "Iris recognition system based on fractal dimensions using improved box counting," Journal of Information Science and Engineering, vol. 32, pp. 275-290, 2019.

[27] S. M. Prigarin, K. Hahn, and G. Winkler, "Comparative analysis of two numerical methods to measure hausdorff dimension of the fractional brownian motion," Siberian Journal of Numerical Mathematics, vol. 11, no. 2, pp. 201-218, 2008.

[28] H. Ding, L. Yang, L. Dong Ze, H. Chao, and L. Ling lin, “3D numerical modeling methods to characterize real aggregate shapes," Journal of Building Materials, vol. 3, pp. 339-344, 2017.
[29] R. D. Peng, H. P. Xie, and Y. Ju, "Computation method of fractal dimension for 2D digital image," Journal of China University of Mining \& Technology, vol. 33, pp. 19-24, 2004.

[30] R. D. Peng, Y. C. Yang, Y. Ju, L. T. Mao, and Y. M. Yang, "Computation of fractal dimension of rock pores based on gray CT images," Chinese Science Bulletin, vol. 56, no. 31, pp. 3346-3357, 2011.

[31] Y. C. Yang, R. D. Peng, and H. W. Zhou, "Computation of fractal dimension for digital Image in a 3D space," Journal of China University of Mining \& Technology, vol. 2, pp. 251-258, 2009.

[32] S. Yang and L. Y. Shao, "Estimation of fractal dimensions of images based on MATLAB," Journal of China University of Mining \& Technology, vol. 35, pp. 478-482, 2006.

[33] S. S. Jin, J. X. Zhan, C. Z. Chen, and W. L. Chen, "Study of pore fractal characteristic of cement mortar," Journal of Building Materials, vol. 1, pp. 92-97, 2011.

[34] X. Zhang, T. H. Huang, Y. J. Zhang, H. Gao, and M. Jiang, "Image-pro plus analysis of pore structure of concrete," Journal of Building Materials, vol. 1, pp. 177-182, 2015.

[35] K. Zhang and S. Wang, "Research on the pore structure of the eggshell based on fractal theory," Journal of Food Agriculture \& Environment, vol. 10, pp. 517-520, 2012.

[36] V. Marcelino, V. Cnudde, S. Vansteelandt, and F. Caro, "An evaluation of $2 \mathrm{D}$-image analysis techniques for measuring soil microporosity," European Journal of Soil Science, vol. 58, no. 1, pp. 133-140, 2007.

[37] I. Alfonso, A. Beltran, M. Abatal et al., "Fractal dimension determination of rock pores by multi-scale analysis of images obtained using OM, SEM and XCT," Fractals-Complex Geometry Patterns and Scaling in Nature and Society, vol. 26, no. 5, article 1850067, 2018.

[38] K. Deng, D. Pan, X. Li, and F. Yin, "Spark testing to measure carbon content in carbon steels based on fractal box counting," Measurement, vol. 133, pp. 77-80, 2019.

[39] L. H. Yu, H. Ou, and Q. P. Duan, "Research on pore volume fractal dimension and its relation to pore structure and strength in cement paste with perlite admixture," Journal of Materials Science and Engineering, vol. 25, pp. 201-204, 2007.

[40] C. Xie, Q. C. Wang, S. Li, and B. Hui, "Relations of pore fractral dimension to pore structure and compressive strength of concrete under different water to binder ratio and curing condition," Bulletin of the Chinese Ceramic Society, vol. 34, pp. 3695-3702, 2015.

[41] C. M. Pang and W. Shaohua, "Void characterization and effect on properties of foam concrete," Journal of Building Materials, vol. 20, pp. 93-98, 2017. 


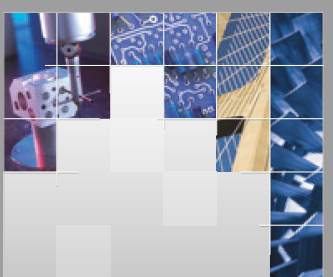

\section{Enfincering}
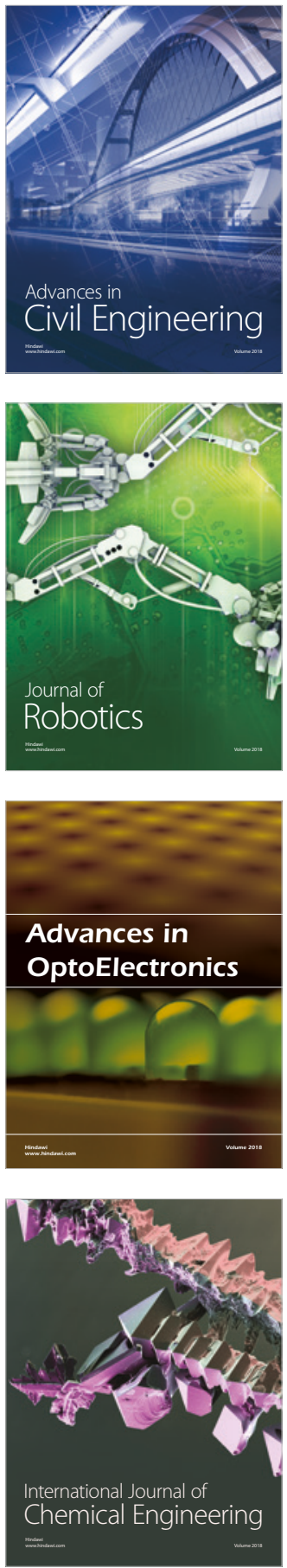

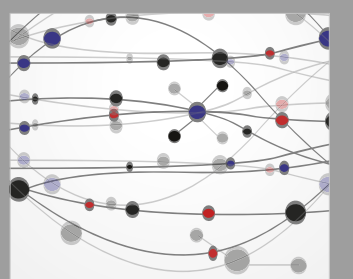

\section{Rotating \\ Machinery}

The Scientific World Journal

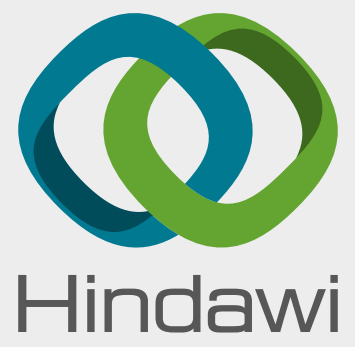

Submit your manuscripts at

www.hindawi.com
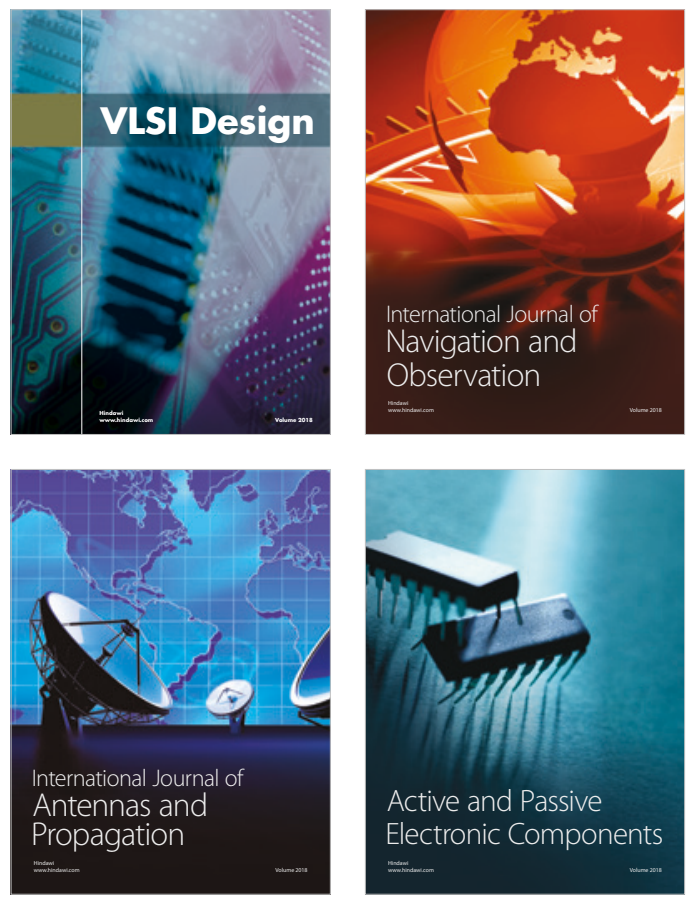
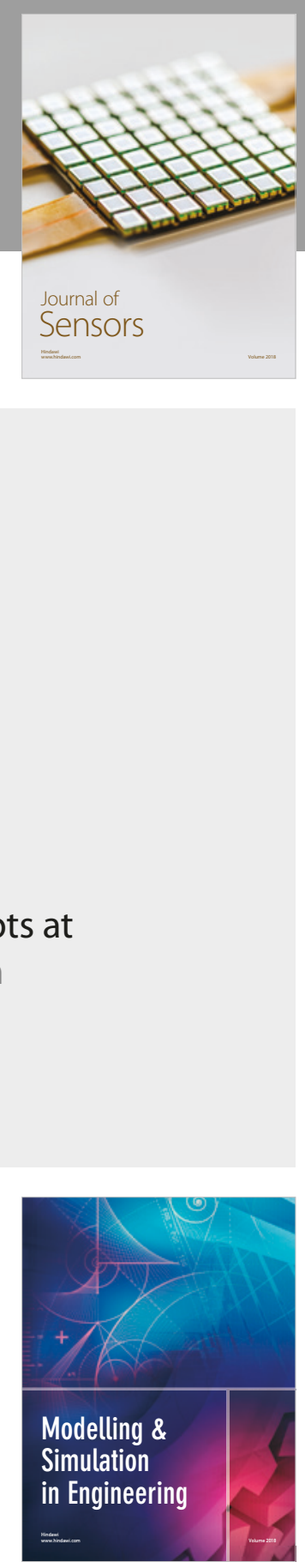

\section{Advances \\ Multimedia}
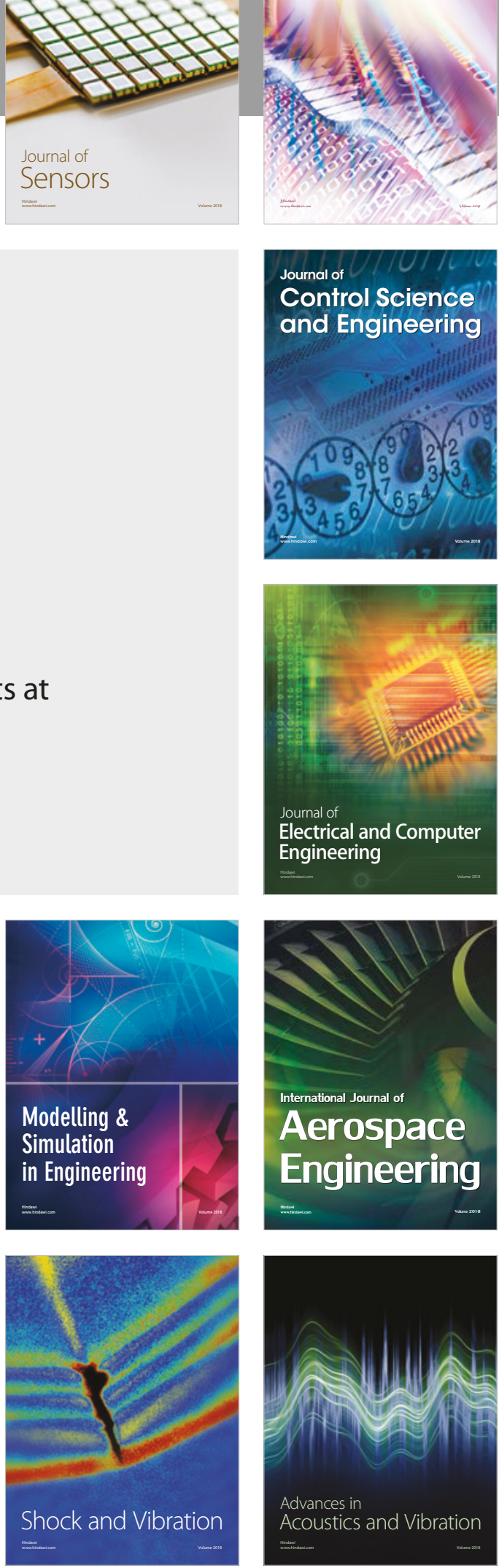